\title{
Impacts of air pollution on COVID-19 case fatality rate: a global analysis
}

\author{
Chao $\mathrm{Li}^{1} \cdot$ Shunsuke Managi ${ }^{1}$
}

Received: 10 September 2021 / Accepted: 28 December 2021 / Published online: 4 January 2022

(c) The Author(s), under exclusive licence to Springer-Verlag GmbH Germany, part of Springer Nature 2022

\begin{abstract}
The coronavirus disease 2019 (COVID-19) pandemic is still rapidly spreading globally. To probe high-risk cities and the impacts of air pollution on public health, this study explores the relationship between the long-term average concentration of air pollution and the city-level case fatality rate (CFR) of COVID-19 globally. Then, geographically weighted regression (GWR) is applied to examine the spatial variability of the relationships. Six air pollution factors, including nitrogen dioxide $\left(\mathrm{NO}_{2}\right)$, sulfur dioxide $\left(\mathrm{SO}_{2}\right)$, ozone $\left(\mathrm{O}_{3}\right), \mathrm{PM}_{2.5}$ (particles with diameter $\left.\leq 2.5 \mu \mathrm{m}\right), \mathrm{PM}_{10}$ (particles with diameter $\leq 10 \mu \mathrm{m}$ ), and air quality index (AQI), are positively associated with the city-level COVID-19 CFR. Our results indicate that a 1-unit increase in $\mathrm{NO}_{2}$ (part per billion, $\mathrm{PPB}$ ), $\mathrm{SO}_{2}(\mathrm{PPB}), \mathrm{O}_{3}(\mathrm{PPB}), \mathrm{PM}_{2.5}$ (microgram per cubic meter, $\left.\mu g / \mathrm{m}^{3}\right), \mathrm{PM}_{10}\left(\mu g / \mathrm{m}^{3}\right.$ ), AQI (score), is related to a $1.450 \%, 1.005 \%, 0.992 \%, 0.860 \%, 0.568 \%$, and $0.776 \%$ increase in the city-level COVID-19 CFR, respectively. Additionally, the effects of $\mathrm{NO}_{2}, \mathrm{O}_{3}, \mathrm{PM}_{2.5}$, AQI, and probability of living with poor AQI on COVID19 spatially vary in view of the estimation of the GWR. In other words, the adverse impacts of air pollution on health are different among the cities. In summary, long-term exposure to air pollution is negatively related to the COVID-19 health outcome, and the relationship is spatially non-stationary. Our research sheds light on the impacts of slashing air pollution on public health in the COVID-19 pandemic to help governments formulate air pollution policies in light of the local situations.
\end{abstract}

Keywords COVID-19 $\cdot$ Case fatality rate $\cdot$ Air pollution $\cdot$ Spatial variability

\section{Introduction}

The coronavirus disease 2019 (COVID-19) pandemic is still rapidly spreading globally and will give rise to more deaths (Chang et al. 2020; Hsiang et al. 2020). As of 30 June 2021, cumulative confirmed cases of COVID-19 have reached over 182.0 million worldwide, with more than 3.9 million deaths (WHO: https://covid19.who.int/). Previous studies proposed that almost a quarter of hospital-admitted patients needed intensive care due to the symptoms of respiratory complications, even though most other patients just had a mild illness (Wang et al. 2020). In this way, prioritizing limited medical resources to the vulnerable areas could curb deaths to some extent. Moreover, several studies illustrated that air pollution

Responsible Editor: Lotfi Aleya

Shunsuke Managi

managi@doc.kyushu-u.ac.jp

1 Urban Institute \& School of Engineering, Kyushu University, 744 Motooka, Nishi-ku, Fukuoka 819-0395, Japan was positively related to the risk of death after being infected by COVID-19 (Jiang and Xu 2021; Travaglio et al. 2021; Zhang et al. 2021; Zheng et al. 2021). To provide helpful information for mitigating the adverse impact of COVID-19 and reducing economic and social costs (Guo et al. 2020; Ikram et al. 2020, 2021; Nakamura and Managi 2020; Yoo and Managi 2020), we aim to explore the global relationship between air pollution and the COVID-19 health outcome.

Air pollution, including $\mathrm{PM}_{10}$ (particles with diameter $\leq 10 \mu \mathrm{m}$ ), $\mathrm{PM}_{2.5}$ (particles with diameter $\leq 2.5 \mu \mathrm{m}$ ), sulfur dioxide $\left(\mathrm{SO}_{2}\right)$, nitrogen dioxide $\left(\mathrm{NO}_{2}\right)$, and ozone $\left(\mathrm{O}_{3}\right)$, adversely impacts both human physical health by causing nonmalignant respiratory deaths, lung cancer, and cardiovascular disease (Brunekreef and Holgate 2002) and mental health, by yielding depression (Silva Moreira et al. 2021; Xue et al. 2021). The adverse effects of long-term exposure to air pollution are irreversible because air pollution makes viruses easier to invade airway epithelial cells (Cruz-Sanchez et al. 2013) and hampers key inflammatory mediators (Popovic et al. 2019). Furthermore, long-term exposure to air pollution is also associated with other chronic diseases, such as chronic obstructive 
pulmonary disease and cerebrovascular disease, among others (Lelieveld et al. 2015). Air pollution, such as $\mathrm{PM}_{2.5}$ and $\mathrm{PM}_{10}$, entering the lungs could induce systemic oxidative stress and inflammation that lead to various pathological processes of cerebrovascular diseases, including increased thrombosis, hypercoagulability, and endothelial dysfunction, among others (Chin 2015). The adverse health impacts of air pollution eventually exacerbate the severity of symptoms and shrink the probability of recovery after the infection (Benmarhnia 2020; Magazzino et al. 2020; Wu et al. 2020) because the COVID19 virus could make cardiovascular disorders or/and other comorbidities worse (Nishiga et al. 2020; Wisnu Wardana and Rosyid 2021). Moreover, several reports turned out that air pollution was correlated with mental disorders (Buoli et al. 2018). Mental disorders might slash the confidence in recovery or influence the attitude towards the disease after being infected by COVID-19 (Slater et al. 2020). Therefore, the people exposed to air pollution for the long term are at stake after the infection of COVID-19.

Understanding the relationship between the local COVID19 health outcome and air pollution can help policymakers predict the health burdens (Fernández et al. 2021; Lee et al. 2021). Every society in this world is considering the trade-off between health benefits and economic as well as social costs (Achebak et al. 2021; Guan et al. 2020; Hsiang et al. 2020; Yalaman et al. 2021). To temper the negative impacts and curb the deaths due to COVID-19, strict legislation, enough personal protective equipment, and vaccines should be prioritized in high-risk areas. Furthermore, previous studies regarding the relationship between air pollution and the health outcome of COVID-19 mainly concentrate on a single country or region, such as China (Zhang et al. 2021), the USA (Wu et al. 2020), Italy (Zoran et al. 2020), Spain (Achebak et al. 2021), and England (Travaglio et al. 2021), among others (Ogen 2020). Almost all these studies put forward a negative correlation between air pollution and the COVID-19 health outcome, but the relationship coefficients in each study are various. Therefore, a global analysis of the relationship is desired. In addition, the local COVID-19 health outcome might be reflective of the average health status in the regions (Mollalo et al. 2021). Thus, the spatial variability of the COVID-19 health outcome might partially show the irreversible negative impacts of air pollution on public health. This variability could also help the public and governments notice the perils of air pollution, understand the spatial distributions of health status, and relocate the medical sources even after the COVID-19 pandemic.

\section{Materials and methods}

\section{Materials}

\section{City-level case fatality rate of COVID-19}

The dependent variable is the city-level case fatality rate (CFR). The observed COVID-19 CFR is the percentage of recorded deaths in confirmed cases during a particular period (Cao et al. 2020). In previous research, several health outcome indicators of COVID-19 are widely used, including mortality (Achebak et al. 2021; Fernández et al. 2021; Jiang and Xu 2021), incidence (Li et al. 2020; Zhu et al. 2020; Zoran et al. 2020), and CFR (Mollalo et al. 2021). The COVID-19 CFR is on behalf of the risk of death after the infection (Fisman et al. 2020; Shim 2021). Mortality and incidence are relatively influenced more by the prevention and control regulations than the CFR. For instance, the mortality and incidence in China are obviously lower than they in the USA, due to the strict lockdown policies in China. Yet, the COVID-19 CFRs in these two countries are close because the CFR primarily presents the medical level and average health status. The data source is the Oxford COVID-19 Government Response Tracker, using the R package "COVID-19" (Data sources are listed in Table S1). The mean of the CFRs in our research is $1.922 \%$, close to the global value $(2.169 \%$, as of 30 June 2021). The CFRs range from 9.506 to almost 0 (Table 1: descriptive statistics of cities).

The city-level data are not perfectly recorded in some countries, so we use upper-level data, such as state-/province- or even national-level data, to substitute for the missing city-level data (Table S2: data level and number of cities; Fig. 1 shows the spatial distribution of city-level CFR). In the current data set, seemingly, most countries only have the country-level COVID-19 CFRs (Table S2). However, over half of these countries have no more than five cities' data. Furthermore, though using country-level data might reduce the accuracy of the analysis, it could guarantee that most developing countries are put into the study. In addition, we also try to detect the relationship between the countrylevel CFR and the medians of air pollution concentration in countries' main cities (Table S3). Yet, nothing is significant. It is reasonable for several reasons. First, the air pollution measurements are all in the important cities in this data set, which cannot reflect the whole country. At least, the other rural areas are ignored. Secondly, the population density and age structure of the main cities are different from the countries'. Due to the results of country-level regression, we eventually employ the city-level regression.

In order to confirm whether the country-level CFR could reflect the city-level CFR, we check the standardized 
Table 1 Descriptive statistics of cities

\begin{tabular}{|c|c|c|c|c|c|c|c|}
\hline Variable name & Obs & Mean & SD & Min & 1st quantile & 3rd quantile & Max \\
\hline City-level CFR (\%) & 575 & 1.922 & 1.636 & 0.000 & 0.917 & 2.581 & 9.506 \\
\hline Average concentration of $\mathrm{NO}_{2}(\mathrm{PPB})$ & 539 & 10.741 & 6.122 & 0.680 & 6.891 & 13.295 & 62.963 \\
\hline Average concentration of $\mathrm{SO}_{2}(\mathrm{PPB})$ & 510 & 5.246 & 9.946 & 0.000 & 1.624 & 5.281 & 103.567 \\
\hline Average concentration of $\mathrm{O} 3$ (PPB) & 526 & 20.579 & 8.887 & 0.000 & 15.912 & 24.639 & 124.515 \\
\hline Average concentration of $\mathrm{PM}_{2.5}\left(\mu \mathrm{g} / \mathrm{m}^{3}\right)$ & 559 & 58.187 & 30.616 & 0.877 & 35.716 & 73.117 & 173.151 \\
\hline Average concentration of $\mathrm{PM}_{10}\left(\mu \mathrm{g} / \mathrm{m}^{3}\right)$ & 539 & 29.086 & 19.492 & 1.000 & 15.849 & 37.706 & 139.048 \\
\hline Average AQI & 593 & 27.772 & 18.111 & 0.0005 & 16.284 & 36.906 & 138.787 \\
\hline Probability of living with poor AQI (0-1) & 593 & 0.145 & 0.214 & 0.000 & 0.005 & 0.217 & 0.963 \\
\hline Average temperature $\left({ }^{\circ} \mathrm{C}\right)$ & 618 & 15.700 & 5.853 & -3.483 & 11.698 & 18.542 & 42.282 \\
\hline Average atmospheric pressure $(\mathrm{hPa})$ & 617 & 1,002 & 47 & 653 & 1,010 & 1,016 & 1,100 \\
\hline Average humidity (\%) & 618 & 66.175 & 13.009 & 10.093 & 58.063 & 75.260 & 92.533 \\
\hline Days of InMR & 578 & 265.661 & 157.548 & 0.000 & 133.250 & 435.000 & 489.000 \\
\hline Percentage of male & 618 & 6.305 & 1.175 & 3.102 & 5.466 & 7.132 & 9.382 \\
\hline Logarithm of population density $\left(1000 / \mathrm{km}^{2}\right)$ & 618 & 42.141 & 6.721 & 24.857 & 37.142 & 46.938 & 69.656 \\
\hline Percentage of population $15-44$ & 618 & 24.802 & 4.660 & 6.078 & 21.541 & 27.687 & 42.604 \\
\hline Percentage of population $45-64$ & 618 & 14.750 & 6.789 & 1.383 & 8.824 & 19.711 & 35.742 \\
\hline Percentage of population $\geq 65$ & 618 & 2.306 & 0.079 & 1.951 & 2.258 & 2.364 & 2.458 \\
\hline Logarithm of GDP per capita (PPP) & 575 & 1.922 & 1.636 & 0.000 & 0.917 & 2.581 & 9.506 \\
\hline
\end{tabular}

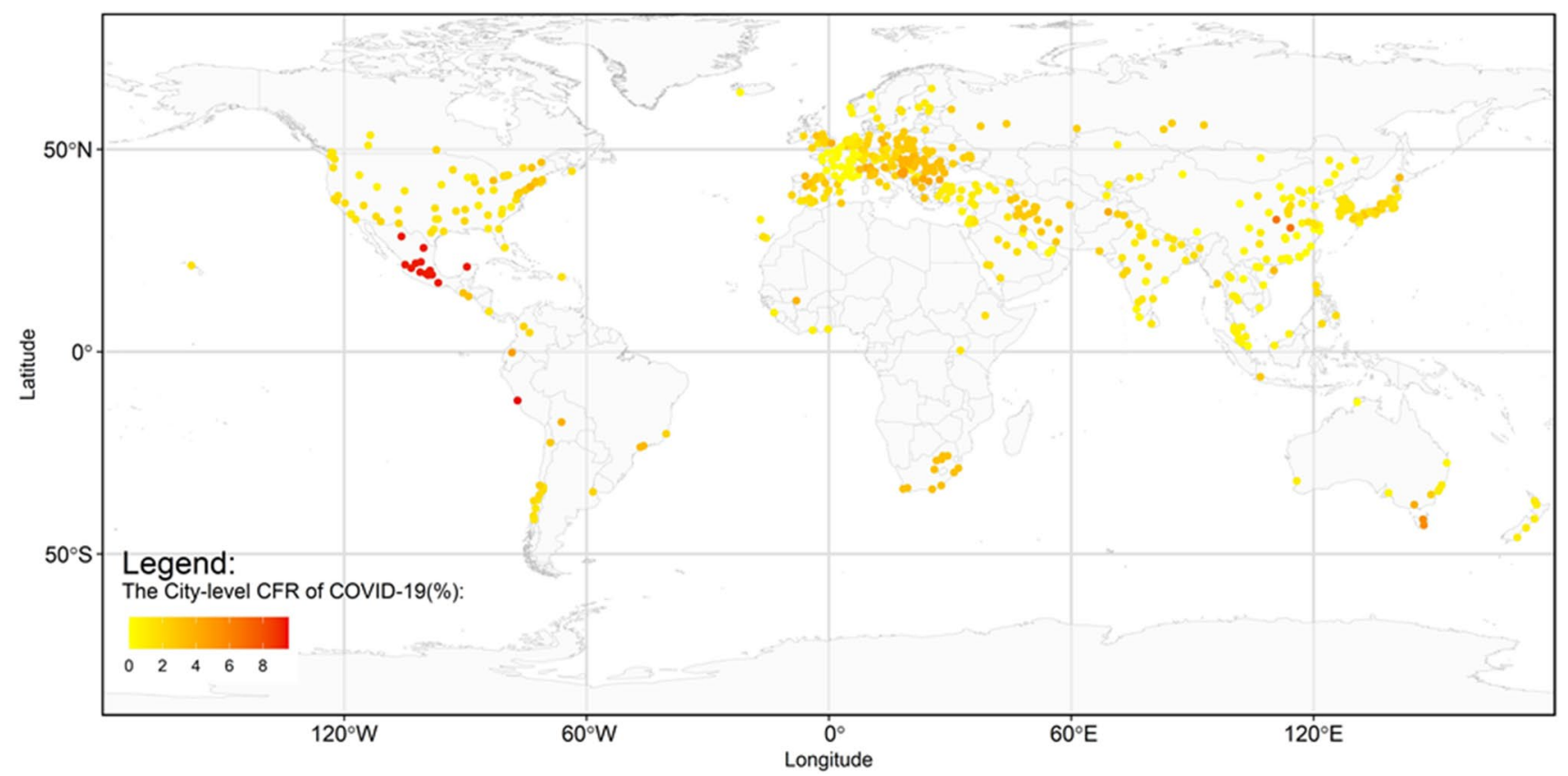

Fig. 1 The spatial distribution of the city-level CFR of COVID-19

difference between the country-level CFR with the mean of city-level CFR of the countries with city-level CFR in our data set, including Austria, Chile, Germany, and the USA, among others. The standardized difference is defined as the absolute value of the quotient of the difference between the country-level CFR with the mean of city-level CFR of a specific country and the standard deviation of city-level CFR. The equation is listed as follows:

$\operatorname{SDiff}_{c}=\left|\frac{\operatorname{CoCFR}_{c}-\operatorname{mean}\left(\operatorname{CiCFR}_{c}\right)}{\operatorname{sd}\left(\operatorname{CiCFR}_{c}\right)}\right|$ 
where $S \operatorname{Diff} f_{c}$ is the standardized difference of country $c$, $\operatorname{CoCFR}_{c}$ is the country-level CFR of country $c, C_{i C F R_{c}}$ is the city-level CFR of country $c$ in our data set, and $s d$ and mean are the functions to obtain the standard deviation and mean, respectively. If the standardized difference of a certain county is slight, the country-level CFR is very similar to the mean of city-level CFR. The result shows that the largest standardized difference is 0.728 from Chile, while the smallest one is 0.022 from the USA. Because the largest standardized difference is still lower than one standard deviation, the country-level data can represent the missing city-level data to some degree.

\section{Air pollution data}

The air pollution data are the atmospheric concentrations of several air pollutants, including $\mathrm{PM}_{2.5}, \mathrm{PM}_{10}, \mathrm{SO}_{2}, \mathrm{NO}_{2}$, and $\mathrm{O}_{3}$ (Data sources is listed in Table S1), Air Quality Index (AQI), and probability of living with poor AQI in more than 600 major cities of roughly 90 countries from 2015 to 2020 (Spatial distributions of air pollution factors are illustrated in Fig. 2). $\mathrm{PM}_{2.5}, \mathrm{PM}_{10}, \mathrm{SO}_{2}, \mathrm{NO}_{2}$, and $\mathrm{O}_{3}$ are the means of every record in the past 5 years. It must be mentioned that the records in 2019 and 2020 are the medians of each air pollutants in $24 \mathrm{~h}$, while in other years, the periods might be longer. Furthermore, most cities have several measurement points. The medians of air pollution are also based on the data from different measurement points in a specific city. The units of each type of air pollutant are transformed according to the United States Environmental
Protection Agency requirements. The transformation process is achieved by the data provider, the World Air Quality Project. The units of $\mathrm{PM}_{2.5}$ and $\mathrm{PM}_{10}$ are micrograms per cube meter $\left(\mu \mathrm{g} / \mathrm{m}^{3}\right)$; the units of $\mathrm{SO}_{2}, \mathrm{NO}_{2}$, and $\mathrm{O}_{3}$ are part per billion (PPB).

Because most of the counties in our data set do not provide AQI, we use the concentrations of air pollutants to calculate the AQI based on European Union regulations and previous studies (Zoran et al. 2020). The AQI is estimated as follows:

$\mathrm{AQI}=\operatorname{Max}\left(\frac{\mathrm{O}_{3}}{100}, \frac{N O_{2}}{90}, \frac{P M_{10}}{50}, \frac{S O_{2}}{125}, \frac{\mathrm{CO}}{10,000}\right) \times 50$

where $\mathrm{O}_{3}, \mathrm{NO}_{2}, \mathrm{PM}_{10}, \mathrm{SO}_{2}$, and $\mathrm{CO}$ (carbon monoxide) represent the medians of each type of air pollution in a certain period, which is usually 1 day. However, because not all cities measure all those five air pollutants, any missing type of air pollution should be ignored. Based on the EU regulations and previous studies (Zoran et al. 2020), when AQI is higher than 50 , the air quality would be classified as poor or very poor. The probability of living with poor AQI is calculated as follows:

PoorAQI $=\frac{\text { Count }(A Q I>50)}{\text { Count }} \times 100 \%$

where PoorAQI represents the probability of living with poor AQI, Count $(A Q I>50)$ represents the days of poor AQI, and Count represents the total days in the data set (Table 1: descriptive statistics of cities).

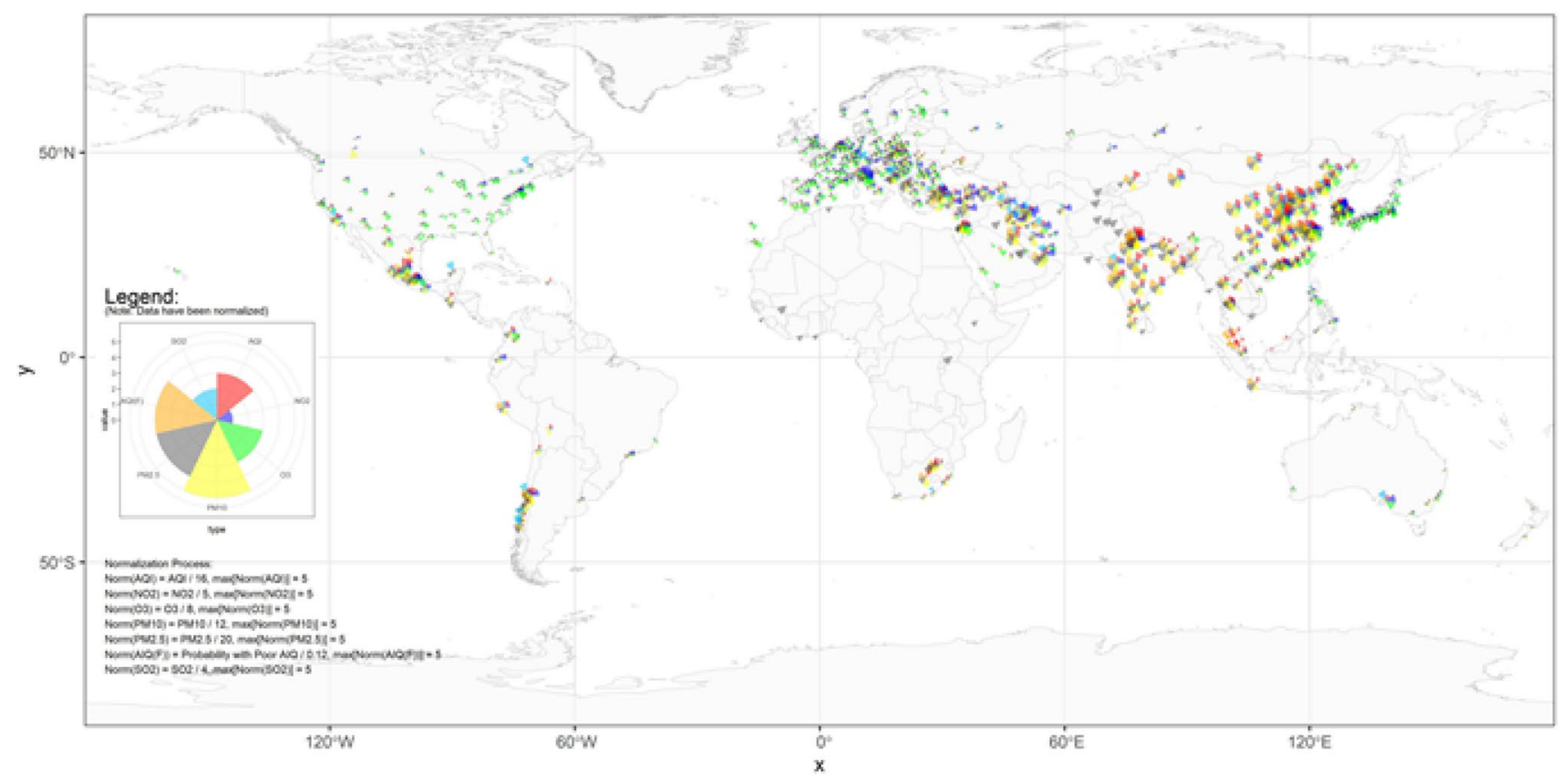

Fig. 2 The spatial distribution of $\mathrm{NO}_{2}, \mathrm{SO}_{2}, \mathrm{O}_{3}, \mathrm{PM}_{2.5}, \mathrm{PM}_{10}$, AQI concentrations, and probability of living with Poor AQI 


\section{Other control variables}

Ten other control variables are priced in at the beginning of this study. Meteorological variables, such as humidity, temperature, and atmospheric pressure, are related to the health outcomes of COVID-19 (Irfan et al. 2021; McClymont and $\mathrm{Hu} 2021$; Wu et al. 2020). Population age composition also impacts the city-level CFR of COVID-19 since the immune system of the elderly is relatively weaker than that of young people (Ioannidis et al. 2020; Liu et al. 2020; Onder et al. 2020; Zheng et al. 2021). To obtain the population age composition data, we use the city location points to generate 0.25 arc degree (roughly $25 \mathrm{~km}$ ) buffers. Then, we calculate the population in each age range based on the grid data with a 1-km resolution from "WorldPop" (Table S1: data source) (WorldPop 2019). In the meanwhile, the percentage of male and population density in the buffers are acquired. We estimate the GDP per capita of each city using a similar method, based on the grid data published in Scientific Data (Kummu et al. 2018). Here, the GDP per capita we use is the purchasing power parity in constant 2011 international USD. Internal movement restrictions (InMR) and international movement restrictions (IMR) are effective policies controlling COVID-19. The InMR and IMR are obtained from Oxford COVID-19 Government Response Tracker. However, InMR and IMR are highly similar. To avoid the impact of multicollinearity, we only employ the InMR in our statistical analyses (Table 1: descriptive statistics of cities; Table S1: data source).

\section{Methods}

\section{Mixed-effects model (MEM)}

We perform ordinary least square (OLS) regression at first, but the residuals of OLS are not normally distributed. To solve this problem, we exploit the MEM with random intercepts. From a general perspective, the policies about prevention and control are consistent in the same country (Yalaman et al. 2021). In this way, the COVID-19 CFR is related to countries, and the country variable should be used to determine the random intercepts. Nevertheless, we have only one or a few cities in many countries, so using the random intercepts based on the country variable is not statistically rational. According to Moran's I test, a previous study demonstrated the spatial autocorrelation of the country-level CFRs (Cao et al. 2020). In other words, the country-level CFRs are spatially clustering, and according to the figure in the research, there is a similarity of the CFRs within each continent (Cao et al. 2020). The city-level COVID-19 CFRs in each continent are relatively similar, while the difference is evident between different continents (Fig. S1). To slash the sum of square residuals in the regression, we employ
MEM with random intercepts based on the continent variable. In other words, except the intercept, other variables are fixed in the regressions. The formula is defined as follows:

$C F R_{i j}=\beta_{0 j}+\beta_{1} A P_{i j}+\beta_{2} D S C_{i j}+\varepsilon_{i}$

where $C F R_{i j}$ is the CFR of COVID-19 in city $i$ in the continent $j ; A P_{i j}$ is the air pollution data of city $i$ in the continent $j$; $\boldsymbol{D S C}_{i j}$ is a vector of demographic, socioeconomic, and clinical condition variables of city $i$ in the continent $j$ as control variables; $\beta_{0 j}$ is the random intercept of the continent $j$; and $\varepsilon_{i}$ is a random error term. $\beta_{1}$ and $\boldsymbol{\beta}_{2}$ are the fixed parameters to be estimated. $\beta_{1}$ is the coefficient of the relationship between air pollution and the COVID-19 CFR. $\boldsymbol{\beta}_{2}$ is a vector of coefficients of the association of the COVID-19 CFR with other variables.

The MEM assumes that there is no spatial difference among the cities in the relationship between air pollution and the city-level CFR, even though the intercepts in each continent are different. However, the effects of air pollution on the health outcome of COVID-19 in each city might be different. Therefore, the spatial variability of this relationship could be more complicated. Furthermore, previous studies indicated that various sources of air pollution were attributable to premature mortality worldwide differently (Dedoussi et al. 2020; Lelieveld et al. 2015). In this study, we try to use a more complex spatial model, i.e., geographically weighted regression (GWR), to detect the spatial variability of the adverse impact of air pollution on the health outcome of COVID-19.

\section{Geographically weighted regression (GWR)}

GWR allows the estimated parameters to vary spatially, while MEM models always suppose that the relationships among variables are stationary ( $\mathrm{Li}$ and Managi 2021a, b; Mollalo et al. 2020, 2021). Hence, the associations among the variables may be different or even opposite in terms of their spatial contexts, especially in large-scale analyses (Fotheringham and Oshan 2016; Li and Managi 2021a, c, Oshan et al. 2020). Moran's I test on the residuals from the OLS regressions is performed to check whether the residuals are spatially clustering. It must be noted that the data used in the OLS regressions have removed the records with the country-level CFRs to delve into deep analyses. All the I statistics from Moran's I tests are significantly positive, indicating that spatial autocorrelation of the residuals exists. Therefore, GWR is a reasonable model to analyze the association of the COVID-19 CFR and air pollution. Basically, the GWR model divides the total data set into a large number of subsamples, based on a fixed distance, technologically called the bandwidth of the GWR. The root mean square prediction error for the 
GWR model is an essential index to acquire the optimal bandwidth. To obtain the optimal bandwidth in the analysis, the cross-validation method based on the root mean square prediction error is employed:

$C V(b)=\frac{m \sum_{i}\left[C F R_{i}-C \hat{F} R_{i}(b)\right]^{2}}{(m-p+1)^{2}}$

where $C V(b)$ is the sum of square residuals of Eq. 5 based on a specific bandwidth $b, m$ is the total data size, $p$ is the number of the parameters including the intercept in the analysis, $C F R_{i}$ is the COVID-19 CFR in the city $i$, and $C \hat{F} R_{i}(b)$ is the predicted CFR in the city $i$ based on the bandwidth $b$. This function is U-shape (Brunsdon et al. 1998; Gollini et al. 2015). The $b$ that makes the $C V(b)$ close to the minimum is considered the optimal bandwidth. In this study, all these functions are from the R package "GWmodel" (Gollini et al. 2015). Based on the optimal bandwidth, the spatially weighted matrix is built automatically. The spatially weighted matrix is calculated as follows:

$\boldsymbol{W}_{i}=\left\{\begin{array}{c}{\left[1-\left(\frac{d}{b}\right)^{2}\right]^{2}, \text { if element }(i) \in \text { sub sample } k} \\ 0, \text { if element }(i) \notin \text { sub sample } k\end{array}\right.$

where $\boldsymbol{d}$ denotes a vector of the distance between city $i$ and other cities in the $k$ th subsample and $b$ denotes the largest distance, namely, the calibrated optimal bandwidth, in the vector $\boldsymbol{d}$. Based on the general form of GWR, the equation in our study is designed as follows:

$C F R_{i k}=\beta_{0 k}+\beta_{1 k} A P_{i k}+\beta_{2 k} \boldsymbol{D S C} \boldsymbol{C}_{i k}+\varepsilon_{i k}, i=1, \ldots, n_{k}$

where $C F R_{i k}$ is the CFR of COVID-19 in city $i$ in the $k$ th regression, $A P_{i k}$ is the air pollution data of city $i$ in the $k$ th regression, $\boldsymbol{D} \boldsymbol{S} \boldsymbol{C}_{i k}$ is a vector of control variables of city $i$ in the $k$ th regression, $n_{k}$ is the data size of the $k$ th subsample, and $\varepsilon_{i k}$ is a random error term. $\beta_{0 k}, \beta_{1 k}$, and $\boldsymbol{\beta}_{2 k}$ are the parameters estimated in the $k$ th regression, because the total sample is divided into several subsamples based on the spatial contexts. To estimate the parameters, each subsample with its spatially weighted matrix is utilized:

$\hat{\boldsymbol{\beta}}_{k}=\left[\boldsymbol{X}_{k}^{T} \boldsymbol{W}_{i} \boldsymbol{X}_{k}\right]^{-1} \boldsymbol{X}_{k}^{T} \boldsymbol{W}_{i} \boldsymbol{C F} \boldsymbol{R}_{k}$

where $\hat{\boldsymbol{\beta}}_{k}$ is a vector of parameters in the $k$ th regression, including $\beta_{0 k}, \beta_{1 k}$, and $\boldsymbol{\beta}_{2 k} ; \boldsymbol{X}_{k}$ is a matrix of independent variables in the $k$ th regression; $\boldsymbol{W}_{i}$ is the spatially weighted matrix of city $i$, based on the distance between the other cities and city $i$; and $\boldsymbol{C F} \boldsymbol{R}_{k}$ is a vector of CFR in cities of the $k$ th subsample.
Quantitative effects of air pollution on COVID-19 CFR

To demonstrate how much air pollution in cities influences the city-level COVID-19 CFR, we define a new index, the case fatality rate ratio (CFRR), to depict the CFR change after increasing air pollution. CFRR is the CFR change ratio after a 1-unit increase in a specific type of air pollution. For the MEM regression results, CFRRs are calculated as follows:

$C F R R_{l}=\frac{\beta_{1 l}}{C F R}$

where $C F R R_{l}$ is the ratio of the predicted CFR change after a 1-unit increase in air pollution of type $l$ to the current average CFR, $\beta_{1 l}$ is the estimated parameter of air pollution of type $l$ by Eq. 4, and $C F R$ is the current average COVID-19 CFR. Additionally, for the GWR results, CFRRs are estimated as follows:

$C F R R_{i l}=\frac{\beta_{1 k l}}{C F R_{i}}$

where $C F R R_{i l}$ is the ratio of the predicted CFR change after a 1-unit increase in air pollution of type $l$ to the COVID-19 CFR in city $i, \beta_{1 k l}$ is the estimated parameter of air pollution of type $l$ in city $i$ in the $k$ th regression by Eq. 7, and $C F R_{i}$ is the COVID-19 CFR in city $i$.

\section{Results}

\section{Air pollution's impacts on the city-level CFR}

The associations of the COVID-19 CFR with seven air pollution factors are investigated. Model 1 to Model 7 are the estimation results based on Eq. 4, taking $\mathrm{NO}_{2}, \mathrm{SO}_{2}$, $\mathrm{O}_{3}, \mathrm{PM}_{2.5}, \mathrm{PM}_{10}$, AQI, and probability of living with poor $\mathrm{AQI}$ as the air pollution variable, respectively (shown in Table 2). Except the probability of living with poor AQI, all other air pollution factors are positively associated with the COVID-19 CFR. The coefficients of $\mathrm{NO}_{2}, \mathrm{SO}_{2}, \mathrm{O}_{3}, \mathrm{PM}_{2.5}$, $\mathrm{PM}_{10}$, and AQI on the COVID-19 CFR are 0.023 (95\% confidence interval: 0-0.045), 0.016 (95\% CI: 0.001-0.030), 0.015 (95\% CI: $0.001-0.030), 0.014$ (95\% CI: $0.007-0.020$ ), 0.009 (95\% CI: $0-0.018$ ), and 0.012 (95\% CI: 0.004-0.021), consistent with previous studies (Achebak et al. 2021; Wu et al. 2020; Zhang et al. 2021; Zoran et al. 2020). The positive coefficients of the relationships between air pollution and the COVID-19 CFR mean that the patients living with severe air pollution for a long time are more likely to die after the infection. Among five main air pollutants, the adverse impact of a 1-PPB increase in the concentration of 
Table 2 MEM results

\begin{tabular}{|c|c|c|c|c|c|c|c|}
\hline & \multicolumn{7}{|c|}{ Dependent variable } \\
\hline & \multicolumn{7}{|c|}{ City-level COVID-19 CFR (\%) } \\
\hline & Model 1 & Model 2 & Model 3 & Model 4 & Model 5 & Model 6 & Model 7 \\
\hline Average concentration of $\mathrm{NO}_{2}$ & $\begin{array}{l}0.023^{* *} \\
(0.012)\end{array}$ & & & & & & \\
\hline Average concentration of $\mathrm{SO}_{2}$ & & $\begin{array}{l}0.016^{* * *} \\
(0.008)\end{array}$ & & & & & \\
\hline Average concentration of $\mathrm{O}_{3}$ & & & $\begin{array}{l}0.015^{* *} \\
(0.007)\end{array}$ & & & & \\
\hline Average concentration of $\mathrm{PM}_{2.5}$ & & & & $\begin{array}{l}0.014^{* * *} \\
(0.003)\end{array}$ & & & \\
\hline Average concentration of $\mathrm{PM}_{10}$ & & & & & $\begin{array}{l}0.009^{*} \\
(0.005)\end{array}$ & & \\
\hline Average AQI & & & & & & $\begin{array}{l}0.012^{* * *} \\
(0.004)\end{array}$ & \\
\hline Probability of living with poor AQI & & & & & & & $\begin{array}{l}0.486 \\
(0.417)\end{array}$ \\
\hline Average temperature & $\begin{array}{l}0.026^{*} \\
(0.015)\end{array}$ & $\begin{array}{l}0.020 \\
(0.015)\end{array}$ & $\begin{array}{l}0.013 \\
(0.016)\end{array}$ & $\begin{array}{l}0.006 \\
(0.014)\end{array}$ & $\begin{array}{l}0.016 \\
(0.014)\end{array}$ & $\begin{array}{l}0.013 \\
(0.013)\end{array}$ & $\begin{array}{l}0.014 \\
(0.013)\end{array}$ \\
\hline Average atmospheric pressure & $\begin{array}{l}0.004^{* * *} \\
(0.001)\end{array}$ & $\begin{array}{l}0.004^{* * *} \\
(0.001)\end{array}$ & $\begin{array}{l}0.004^{* * *} \\
(0.001)\end{array}$ & $\begin{array}{l}0.002^{*} \\
(0.001)\end{array}$ & $\begin{array}{l}0.003^{* *} \\
(0.001)\end{array}$ & $\begin{array}{l}0.003^{\text {*** }} \\
(0.001)\end{array}$ & $\begin{array}{l}0.003^{* *} \\
(0.001)\end{array}$ \\
\hline Average humidity & $\begin{array}{l}-0.033^{\text {*** }} \\
(0.006)\end{array}$ & $\begin{array}{l}-0.041^{* * *} \\
(0.006)\end{array}$ & $\begin{array}{l}-0.038^{* * *} \\
(0.006)\end{array}$ & $\begin{array}{l}-0.037^{* * *} \\
(0.006)\end{array}$ & $\begin{array}{l}-0.034^{* * *} \\
(0.006)\end{array}$ & $\begin{array}{l}-0.035^{* * *} \\
(0.005)\end{array}$ & $\begin{array}{l}-0.037^{* * *} \\
(0.005)\end{array}$ \\
\hline Days of InMR & $\begin{array}{l}0.002^{* * *} \\
(0.001)\end{array}$ & $\begin{array}{l}0.001^{* * *} \\
(0.001)\end{array}$ & $\begin{array}{l}0.002^{* * *} \\
(0.001)\end{array}$ & $\begin{array}{l}0.002^{* * *} \\
(0.001)\end{array}$ & $\begin{array}{l}0.001^{* * *} \\
(0.001)\end{array}$ & $\begin{array}{l}0.002^{* * *} \\
(0.0005)\end{array}$ & $\begin{array}{l}0.001^{* * *} \\
(0.0005)\end{array}$ \\
\hline Percentage of male & $\begin{array}{l}-0.115^{* * *} \\
(0.042)\end{array}$ & $\begin{array}{l}-0.109^{* *} \\
(0.042)\end{array}$ & $\begin{array}{l}-0.098^{* *} \\
(0.043)\end{array}$ & $\begin{array}{l}-0.140^{* * *} \\
(0.041)\end{array}$ & $\begin{array}{l}-0.108^{* * *} \\
(0.041)\end{array}$ & $\begin{array}{l}-0.098^{* *} \\
(0.039)\end{array}$ & $\begin{array}{l}-0.096^{* *} \\
(0.039)\end{array}$ \\
\hline Logarithm of population density & $\begin{array}{l}-0.059 \\
(0.069)\end{array}$ & $\begin{array}{l}0.020 \\
(0.067)\end{array}$ & $\begin{array}{l}0.017 \\
(0.067)\end{array}$ & $\begin{array}{l}-0.061 \\
(0.068)\end{array}$ & $\begin{array}{l}-0.062 \\
(0.066)\end{array}$ & $\begin{array}{l}-0.025 \\
(0.061)\end{array}$ & $\begin{array}{l}-0.006 \\
(0.062)\end{array}$ \\
\hline Percentage of population $15-45$ & $\begin{array}{l}0.096^{* * *} \\
(0.030)\end{array}$ & $\begin{array}{l}0.076^{* * *} \\
(0.030)\end{array}$ & $\begin{array}{l}0.092^{* * *} \\
(0.030)\end{array}$ & $\begin{array}{l}0.077^{* * *} \\
(0.028)\end{array}$ & $\begin{array}{l}0.079^{\text {*** }} \\
(0.029)\end{array}$ & $\begin{array}{l}0.076^{* * *} \\
(0.027)\end{array}$ & $\begin{array}{l}0.074^{* * *} \\
(0.028)\end{array}$ \\
\hline Percentage of population $45-65$ & $\begin{array}{l}0.003 \\
(0.021)\end{array}$ & $\begin{array}{l}-0.015 \\
(0.022)\end{array}$ & $\begin{array}{l}-0.0001 \\
(0.022)\end{array}$ & $\begin{array}{l}-0.012 \\
(0.021)\end{array}$ & $\begin{array}{l}-0.011 \\
(0.021)\end{array}$ & $\begin{array}{l}-0.014 \\
(0.021)\end{array}$ & $\begin{array}{l}-0.010 \\
(0.022)\end{array}$ \\
\hline Percentage of population $\geq 65$ & $\begin{array}{l}0.094^{* * *} \\
(0.028)\end{array}$ & $\begin{array}{l}0.085^{* * *} \\
(0.028)\end{array}$ & $\begin{array}{l}0.090^{* * *} \\
(0.029)\end{array}$ & $\begin{array}{l}0.088^{* * *} \\
(0.028)\end{array}$ & $\begin{array}{l}0.084^{* * *} \\
(0.028)\end{array}$ & $\begin{array}{l}0.088^{* * *} \\
(0.027)\end{array}$ & $\begin{array}{l}0.081^{\text {**** }} \\
(0.027)\end{array}$ \\
\hline Logarithm of GDP per capita & $\begin{array}{l}-9.631^{* * *} \\
(1.393)\end{array}$ & $\begin{array}{l}-9.557^{* * *} \\
(1.441)\end{array}$ & $\begin{array}{l}-10.457^{* * *} \\
(1.440)\end{array}$ & $\begin{array}{l}-4.896^{* * *} \\
(1.350)\end{array}$ & $\begin{array}{l}-6.365^{* * *} \\
(1.333)\end{array}$ & $\begin{array}{l}-7.382^{* * *} \\
(1.223)\end{array}$ & $\begin{array}{l}-7.820^{* * *} \\
(1.228)\end{array}$ \\
\hline Constant & $\begin{array}{l}22.570^{* * *} \\
(3.109)\end{array}$ & $\begin{array}{l}23.380^{* * * *} \\
(3.222)\end{array}$ & $\begin{array}{l}23.715^{* * *} \\
(3.198)\end{array}$ & $\begin{array}{l}15.540^{* * *} \\
(2.985)\end{array}$ & $\begin{array}{l}16.969^{* * *} \\
(3.050)\end{array}$ & $\begin{array}{l}18.078^{* * * *} \\
(2.884)\end{array}$ & $\begin{array}{l}19.489^{* * *} \\
(2.853)\end{array}$ \\
\hline Observations & 497 & 471 & 484 & 516 & 499 & 551 & 551 \\
\hline Log likelihood & -894.792 & -854.077 & -883.382 & -949.486 & -900.490 & -991.081 & -989.714 \\
\hline Akaike inf. crit. & $1,817.584$ & $1,736.154$ & $1,794.763$ & $1,926.972$ & $1,828.979$ & $2,010.162$ & $2,007.429$ \\
\hline Bayesian inf. crit. & $1,876.504$ & $1,794.322$ & $1,853.313$ & $1,986.417$ & $1,887.956$ & $2,070.526$ & $2,067.793$ \\
\hline
\end{tabular}

Note: ${ }^{*} p<0.1,{ }^{* *} p<0.05,{ }^{* * *} p<0.01$

$\mathrm{NO}_{2}$ on the COVID-19 CFR is the strongest. However, the probability of living with poor AQI is not significantly associated with the COVID-19 CFR. The probability of living with poor AQI is unable to exclude the situation that the cities are always with the AQI around 50, but their average AQI is still not high. In this way, the relationship between the COVID-19 CFR and the probability of living with poor $\mathrm{AQI}$ is not significant. 
The results of the control variables in the analysis also make sense. The average atmospheric pressure is positively associated with the COVID-19 CFR. The cities always with a low atmospheric pressure have high altitudes. Normally, the human settlements with high population density and convenient transportation are distributed in the low-altitude areas, where the transmission of COVID-19 is relatively more serious. Furthermore, relatively high air pressure is associated with more medical consultations and harms physical health by inducing chronic obstructive pulmonary disease (Ferrari et al. 2012). In addition, the average humidity is negatively correlated with the COVID-19 CFR. Living in dry air for a long time is related to a high probability of adverse health outcomes after the infection of COVID-19, in line with a previous study (Wu et al. 2020). In fact, high humidity could slash the transmission of COVID-19, even in the humid country, Bangladesh (Haque and Rahman 2020). A relatively lower prevalence of COVID-19 could reduce the pressure on the medical systems to save more patients. Days of InMR are positively associated with the COVID-19 CFR because the cities with severe outbreaks tend to have a longer and stricter lockdown policy, lining up with previous research (Wu et al. 2020). The percentage of male is negatively related to the COVID-19 CFR, but it does not mean that males are less susceptible. Previous studies proposed that the male patients of the COVID-19 are at higher risks of death relative to female patients (Williamson et al. 2020) since female patients have a higher antibody response (Kopel et al. 2020). However, in our data set, there is a significantly positive correlation between the percentage of male and the percentage of the population between 15 and 45 (correlation coefficient $=0.538$ ), and negative correlations among the percentage of male, the percentage of the population between 45 and 65 (correlation coefficient $=-0.290$ ), and the percentage of the population over 65 (correlation coefficient $=-0.501$ ). Therefore, the negative association of the percentage of male with the COVID-19 CFR may be caused by the relative longevity of females. There is no significant relationship between population density and the COVID-19 CFR. The COVID-19 CFR partially represents the proportion of people with underlying diseases in the cities, which is generally not related to population density. The percentages of the population between 15 and 45 and over 65 are positively associated with the COVID-19 CFR. Elders are more vulnerable, tallying with previous studies (Williamson et al. 2020; Wu et al. 2020). Young people are relatively loose in implementing lockdown policies, which might cause more infection ultimately influence the COVID-19 CFR (Cortis 2020). The GDP per capita is negatively correlated with the COVID-19 CFR. Therefore, people living in rich cities have a relatively lower probability of death because, in those cities, the medical system is complete.

To demonstrate the impacts of air pollution on health outcomes in COVID-19, the CFRRs of each air pollution factor are calculated using Eq. 8, based on the parameters estimated by the MEM. The CFRRs of each air pollution factor, their $95 \%$ confidence intervals (CIs), and the $t$-values are listed in Table 3. A 1-PPB increase in the longterm average concentration of $\mathrm{NO}_{2}$ is related to a $1.450 \%$ (95\% CI: 0.002-2.870\%) increase in city-level COVID-19 CFR, according to Model 1. Additionally, the CFRRs of an increase in other air pollution factors, including $\mathrm{SO}_{2}, \mathrm{O}_{3}$, $\mathrm{PM}_{2.5}, \mathrm{PM}_{10}$, and AQI, are 1.005\% (95\% CI: 0.064-1.952\%), $0.992 \%$ (95\% CI: $0.072-1.905 \%), 0.860 \%$ (95\% CI: $0.439-1.270 \%$ ), $0.568 \%$ (95\% CI: -0.028 to $1.156 \%$ ), and $0.776 \%$ (95\% CI: $0.229-1.312 \%$ ), respectively, based on Models 2-6 (shown in Fig. 3). In summary, long-term exposure to high air pollution concentrations is positively associated with the local COVID-19 CFR. Putting it another way, people living with higher air pollution concentrations are more likely to die after infection by the coronavirus and more possible to have other diseases, such as nonmalignant respiratory deaths, lung cancer, and cardiovascular disease, among others.

\section{Spatial variability of air pollution's impacts}

Figure 4 illustrates the spatial distribution of the coefficients of each air pollution factor, estimated by the GWR. The results are spatially non-stationary, i.e., the coefficients are different among cities. Based on the $t$-values of coefficients, the local coefficients of $\mathrm{SO}_{2}$ and $\mathrm{PM}_{10}$ are not significant,
Table 3 Coefficients, CFRR, 95\% confidence intervals, and $t$ value for air pollution factors

\begin{tabular}{llllll}
\hline & Variable & Coefficient & CFRR(\%) & 95\% CI & $t$ value \\
\hline Model 1 & Average concentration of $\mathrm{NO}_{2}$ & $0.023^{* *}$ & 1.450 & $(0.002$ to 2.870$)$ & 1.968 \\
Model 2 & Average concentration of $\mathrm{SO}_{2}$ & $0.016^{* *}$ & 1.005 & $(0.064$ to 1.952$)$ & 2.064 \\
Model 3 & Average concentration of $\mathrm{O}_{3}$ & $0.015^{* *}$ & 0.992 & $(0.072$ to 1.905$)$ & 2.100 \\
Model 4 & Average concentration of $\mathrm{PM}_{2.5}$ & $0.014^{* * *}$ & 0.860 & $(0.439$ to 1.270$)$ & 4.031 \\
Model 5 & Average concentration of $\mathrm{PM}_{10}$ & $0.009^{*}$ & 0.568 & $(-0.028$ to 1.156) & 1.863 \\
Model 6 & Average AQI & $0.012^{* * *}$ & 0.776 & $(0.229$ to 1.312$)$ & 2.788 \\
Model 7 & Probability of living with poor AQI & 0.486 & 30.445 & $(-21.213$ to 80.735) & 1.165 \\
\hline
\end{tabular}

Note: ${ }^{*} p<0.1,{ }^{* *} p<0.05,{ }^{* * * *} p<0.01$ 
Fig. 3 The CFRRs of severn air pollution types

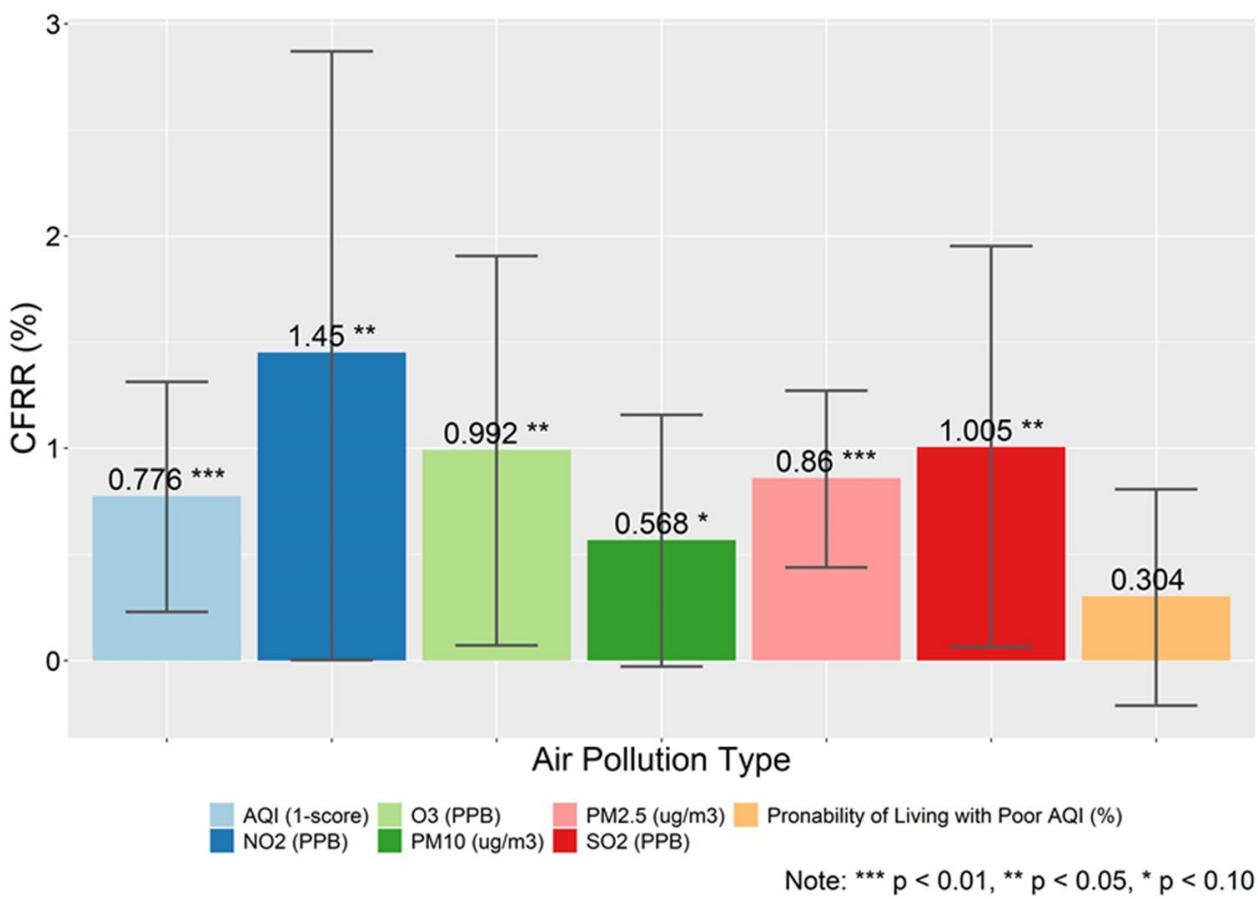

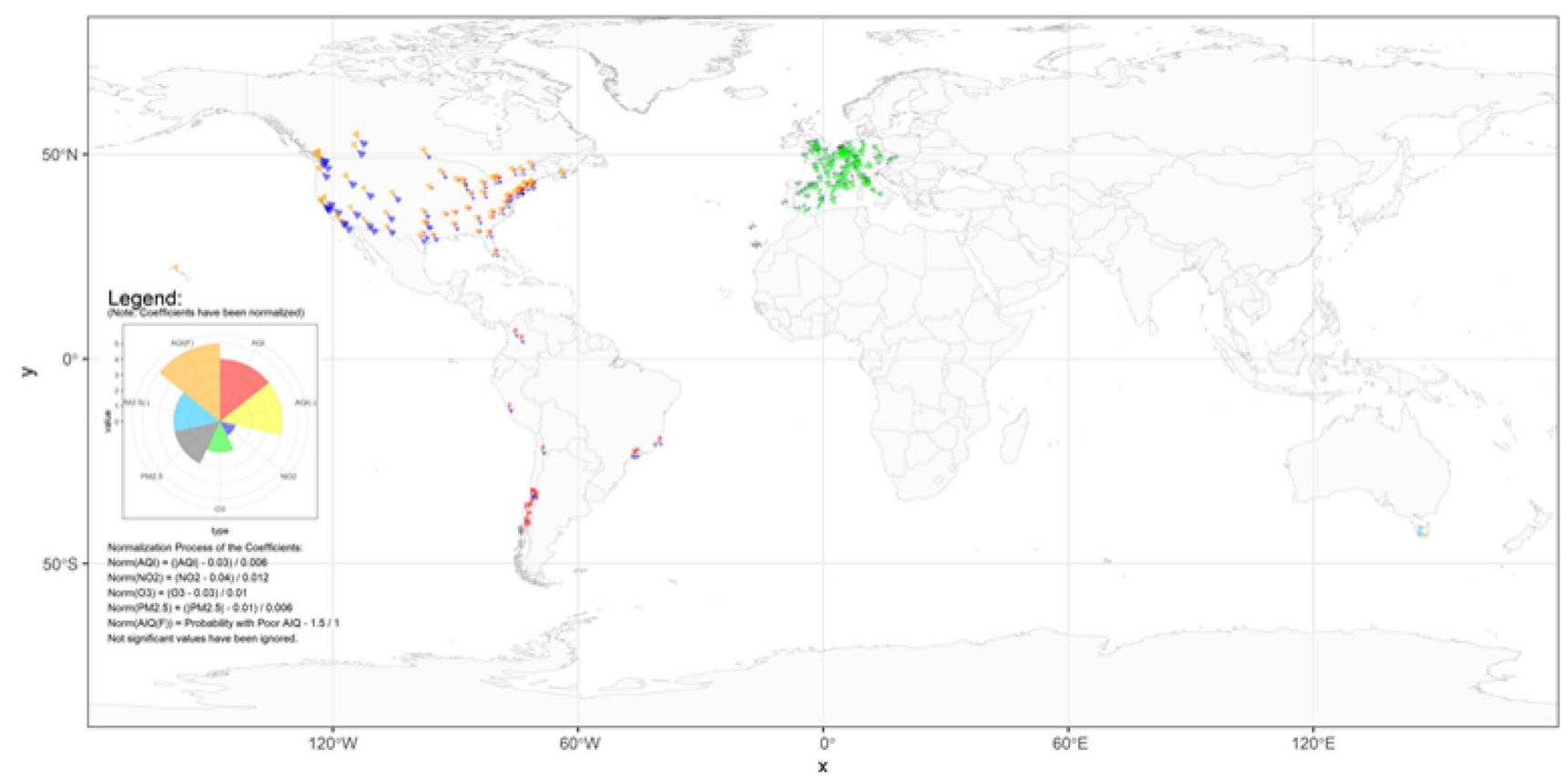

Fig. 4 The spatial distribution of the coefficients of $\mathrm{NO}_{2}, \mathrm{O}_{3}, \mathrm{PM}_{2.5}$, AQI, and probability of Living with Poor AQI

and the local coefficients of other air pollution factors are partially significant. According to GWR results, there is a significant relationship between the COVID-19 CFR and the $\mathrm{NO}_{2}$ concentration in Europe, North America, and South America, shown in Fig. 4. In the Western United States, the negative impacts of $\mathrm{NO}_{2}$ on human health are the strongest. The $\mathrm{O}_{3}$ concentration is significantly associated with the COVID-19 CFR in Europe, especially Western Europe. The situation of the $\mathrm{PM}_{2.5}$ concentration is similar to $\mathrm{O}_{3}$ 's, but the negative relationship between the CFR and the $\mathrm{PM}_{2.5}$ concentration is found in Southern Australia, illustrated in Fig. 4. However, it does not mean that in Australia, air pollution is good for health. Because most patients in Australia concentrate in Victoria, the cities in the Southern part of 
Australia have fewer people infected. Therefore, the CFR in those Southern cities is relatively high because the denominator, the number of confirmed cases, is small (shown in Fig. 1). Furthermore, the cities with data in Australia are far from the cities in the data set, so the local data sets for those cities are limited, based on the bandwidths used in GWR. In Fig. 4, the AQI is positively related to the CFR in North America and South America, while the relationship in Eastern Australia is the opposite. The reason for this negative relationship is the same as the relationship between the $\mathrm{PM}_{2.5}$ concentration and the CFR. The association of the CFR with the probability of living with poor AQI is significant in partial Europe, North America, and South America, in Fig. 4. The negative impacts of the probability of living with poor AQI are the strongest in the Canada and Northern part of the USA.

Figure 5 spatially illustrates the CFRRs of a 1-unit increase in particular air pollution factor, estimated by Eq. 10. The mean of the CFRR of a 1-PPB increase in $\mathrm{NO}_{2}$ is $7.59 \%$, ranging from 0.77 to $34.10 \%$. The means of the CFRRs of a 1-unit increase in $\mathrm{O}_{3}, \mathrm{PM}_{2.5}$, AQI, and probability of living with poor AQI are $12.41 \%$ (1.49-46.44\%), $3.70 \%$ ( -0.59 to $15.04 \%$ ), $2.39 \%$ ( -5.51 to $6.04 \%$ ), and $2.83 \%$ (0.27-10.81\%), respectively. In France, the city-level CFRs are sensitive with the $\mathrm{NO}_{2}, \mathrm{O}_{3}$, and $\mathrm{PM}_{2.5}$ concentration (Fig. 5), because the CFRs in France are relatively lower (Fig. 1) and the coefficients of the relationship between the CFR and air pollution are relatively higher (Fig. 4). In this sense, French air pollution control has been effective in the past 5 years, and people in France do benefit from high air quality. The cities with high positive CFRRs are more easily affected by air pollution because they are relatively cleaner. People could gradually accept air pollution ( $\mathrm{Li}$ and Managi 2021a). It must be noted that the negative values of the CFRRs only exist in Australia and need to be treated carefully because the data sizes are limited.

\section{Policy discussion}

Our analyses provide a critical view of how a range of air pollutants are significantly associated with the health outcomes of COVID-19. This study discusses the negative impact of long-term exposure to air pollution on public health rather than its effects during the COVID-19 pandemic. COVID-19 intensively shows these negative impacts, i.e., the patients infected by COVID-19 with chronic diseases are more likely to die, and this poor health status might be caused by long-term exposure to air pollution. Here, we examine the role of air pollutants on the city-level CFR by employing MEM and GWR. The results indicate that the long-term average concentrations of $\mathrm{NO}_{2}, \mathrm{SO}_{2}, \mathrm{O}_{3}, \mathrm{PM}_{2.5}$, $\mathrm{PM}_{10}$, and $\mathrm{AQI}$ are positively associated with the city-level CFR. Moreover, the relationships between the city-level CFR and air pollutants estimated by GWR show the local significance and spatial variability.

The relationship between long-term exposure to air pollution and mortality risk is plausible for several reasons. Long-term exposure to air pollution causes more chronic diseases, a weaker respiratory system and immune system (Cruz-Sanchez et al. 2013; Popovic et al. 2019), and the

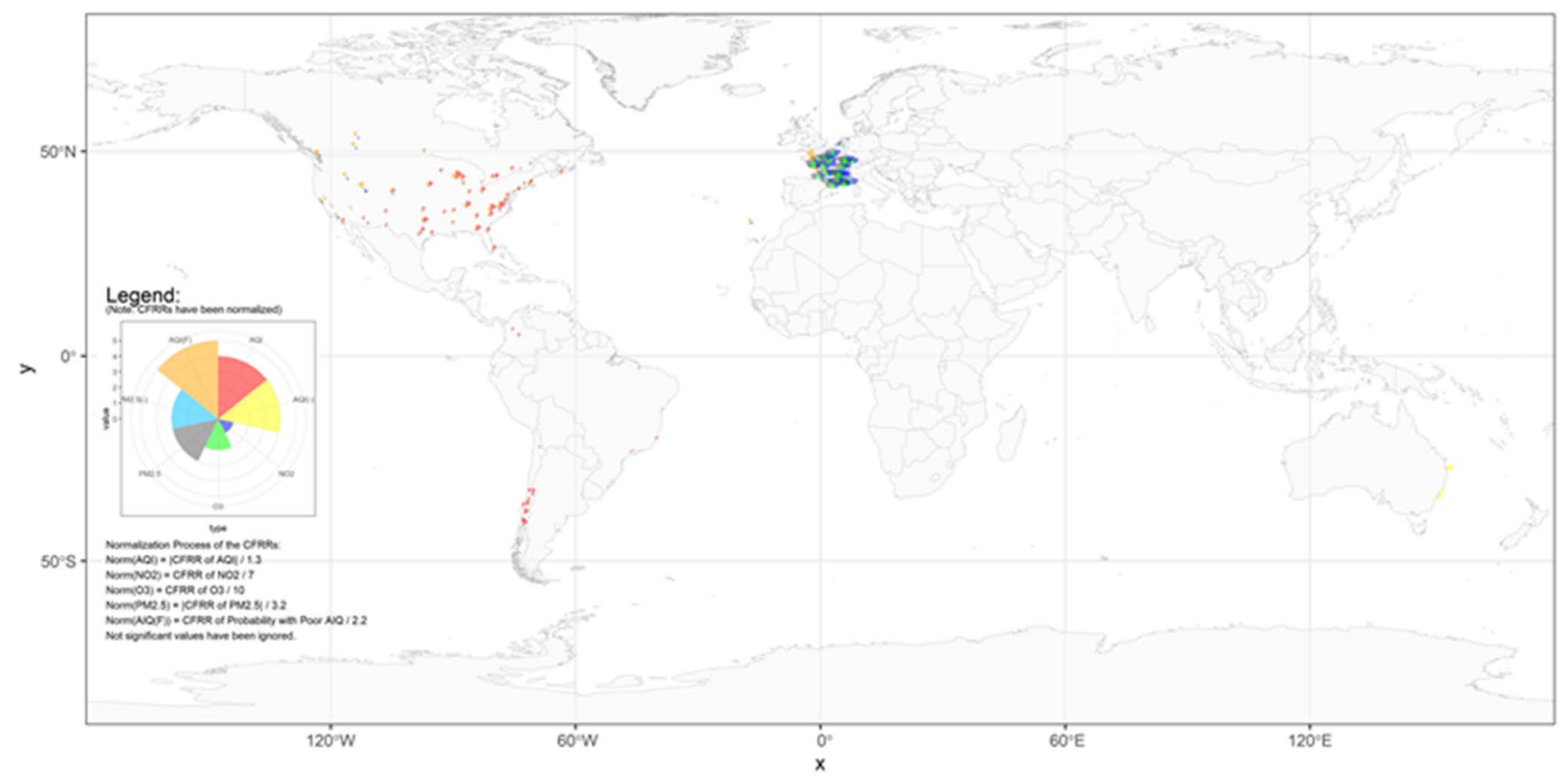

Fig. 5 The spatial distribution of the CFRRs of 1-unit increase of $\mathrm{NO}_{2}, \mathrm{O}_{3}, \mathrm{PM}_{2.5}$, AQI, and probability with poor AQI 
reason for more deaths after being infected by COVID-19 is the poor health status. First, a variety of adverse health outcomes is attributed to long-term exposure to air pollution. Evidence showed that acute respiratory symptoms, exacerbated asthma, and nonfatal heart attacks, among others, were associated with long-term exposure to air pollutants, especially $\mathrm{PM}_{2.5}$ and $\mathrm{O}_{3}$ (Dedoussi et al. 2020; Lelieveld et al. 2015; Pope et al. 2018). The mechanisms of these diseases are as follows: fine particles carry more radioactive elements producing free radicals; destroy the balance of intracellular calcium; and are related to inflammatory injury (Xing et al. 2016). Secondly, chronic diseases exacerbate the severity of symptoms and reduce the probability of recovery after infection (Benmarhnia 2020; Magazzino et al. 2020; Wu et al. 2020). Previous studies indicated that pre-existing mortalities of 20 diseases were spatially associated with COVID-19 mortality (Mollalo et al. 2021), and diabetes, severe asthma, and many other medical conditions are related to COVID-19-related deaths (Williamson et al. 2020). Additionally, previous studies demonstrated that air pollution was directly associated with morbidity ( $\mathrm{Li}$ et al. 2020; Zhang et al. 2020; $\mathrm{Zhu}$ et al. 2020). Specifically, the associations of $\mathrm{PM}_{2.5}$, $\mathrm{PM}_{10}, \mathrm{NO}_{2}, \mathrm{SO}_{2}$, and $\mathrm{O}_{3}$ with confirmed COVID-19 cases or mortalities are positive (Li et al. 2020; Ogen 2020; Zhu et al. 2020; Zoran et al. 2020). Air pollutants, such as $\mathrm{PM}_{2.5}$ and $\mathrm{PM}_{10}$, also influence the coronavirus spread, as the fine particles are considered carriers of the coronavirus (Zhang et al. 2021). To sum up, severe air pollution is positively associated with the COVID-19 CFR.

The spatially significant coefficients of air pollutants are distributed in the lightly polluted cities, especially Europe, North America, and South America. Moreover, the coefficients are spatially different, indicating that air pollutants' effects might be various. For instance, air pollutants and the COVID-19 CFR in Europe, especially France, are low. After reviewing many previous studies, the effects of air pollutants are not totally the same in different countries (Katoto et al. 2021), e.g., China (Zhang et al. 2021; Zhu et al. 2020), the USA (Wu et al. 2020), Europe (Ogen 2020), and the UK (Travaglio et al. 2021), among others. These indicate that the spatial variability of the relationship between air pollution and the COVID-19 health outcome exists. Due to various living environments, the negative impacts of a marginal increase in air pollution are different (Li and Managi 2021a, b). Moreover, the different lifestyles, such as diets (Tilman and Clark 2014), work, and social connections (Imbulana Arachchi and Managi 2021), among others, also cause the variability of health status (Mollalo et al. 2021), and eventually matter to the impacts of air pollution on health. The GWR results illustrate the spatial variability of the relationship between the COVID-19 outcomes and air pollution by the spatially non-stationary air pollution parameters.
Our study implies that policymakers should pay more attention to air pollution. The adverse impacts of air pollution are intensively shown in this catastrophic pandemic, COVID-19. When combating the COVID-19, the policies should be flexible and targeted. In high-risk areas, such as places with severe air pollution, strict legislation, enough personal protective equipment and vaccines are required to avoid the higher mortality. Furthermore, we also should be aware of the trade-off between the environment and the economy to some degree (Guan et al. 2020; Hsiang et al. 2020). The associations of the COVID-19 CFR with air pollution are positive. However, the relationships between the economy and these pollutants are also positive, which indicates that economic development is associated with more air pollution (Zhu et al. 2019). Accordingly, policies reducing air pollution should be treated carefully because the environmental benefit may not completely offset the loss of the economy and society (Magazzino et al. 2021). Moreover, of note, the results also demonstrate that the effects of the different air pollutants have spatial variability. This emphasizes that air pollution may have different degrees of effects on public health globally, so air pollution policies should be adapted to local situations. In a nutshell, the governments and the public should care more about air pollution, even though the concentrations are at unnoticeable levels.

\section{Limitations of this study}

There are several limitations in this research. First, this study focuses on the CFR to indicate the disease fatality. However, the CFR accuracy varies spatially because mortality data are more accurate, while many infected people are never confirmed owing to no obvious symptoms. Even though a reliable data set is used (Oxford COVID-19 Government Response Tracker,) this problem still exists. Second, we could not perform further analysis without the city-level mortality rate and incidence rate due to the lack of an exact city-level population. Third, some sociodemographic and comorbidity characteristics, such as occupational composition and comorbidity mortalities, among others, cannot be obtained, which could also influence the CFR of COVID-19. Fourth, some countries do not have city-level data, so we must use subnational- or national-level data as substitutes. This is the main reason for the clustering residuals, which ultimately are the reason for removing national-level data in the GWR. Fifth, due to a lack of individual-level data, we cannot delve into the physical mechanism of air pollution's impacts on human health. Finally, the heterogeneity of factors within an individual city may be enormous, which is ignored in this study. In the future, the cumulative effects of long-term exposure to air pollution on the immune system should be determined. Furthermore, the impacts of air pollution on coronavirus variants are also an essential 
topic to discuss. Since variants are more likely to survive in patients with weak immune systems, the poor air quality might increase the surviving variants of coronavirus.

\section{Conclusions}

To the best of our knowledge, our study is the first to analyze the global relationship between several air pollution factors and the city-level COVID-19 CFR. Patients who are exposed to air pollution in long term are more likely to die after infection of COVID-19. Our results indicate that a 1-unit increase in $\mathrm{NO}_{2}(\mathrm{PPB}), \mathrm{SO}_{2}(\mathrm{PPB}), \mathrm{O}_{3}(\mathrm{PPB}), \mathrm{PM}_{2.5}\left(\mu \mathrm{g} / \mathrm{m}^{3}\right), \mathrm{PM}_{10}$ $\left(\mu \mathrm{g} / \mathrm{m}^{3}\right)$, and AQI (score), is related to a $1.450 \%, 1.005 \%$, $0.992 \%, 0.860 \%, 0.568 \%$, and $0.776 \%$ increase in the citylevel COVID-19 CFR, respectively and globally. Additionally, the effects of $\mathrm{NO}_{2}, \mathrm{O}_{3}, \mathrm{PM}_{2.5}$, AQI, and probability of living with poor AQI on COVID-19 spatially vary because of the difference in living environments, lifestyle, and average health status globally. Theoretically, the impacts of reducing air pollution on public health are positive during the COVID-19 pandemic, and long-term exposure to air pollution might cause permanent health damage. Additionally, our results have several practical implications. First, decreasing air pollution is significant in improving human health. People in some regions with poor air quality are more likely to die after the infection of COVID-19. Secondly, due to different environments and lifestyles, the impacts of air pollution on health spatially vary. Thus, air pollution policies should be formulated according to local situations to balance the economic costs and health benefits. The air pollution restrictions should be stricter in severely polluted areas.

Supplementary Information The online version contains supplementary material available at https://doi.org/10.1007/s11356-021-18442-x.

Acknowledgments The authors gratefully acknowledge all the support, financial or otherwise, in enabling the work here to be carried out.

Author contribution C.L. conducted the analyses and wrote the manuscript. S.M. conceived of the study and edited the manuscript. All authors reviewed the manuscript.

Funding This research was supported by the following funding agencies: JSPS KAKENHI (Grant No. JP20H00648), the Environment Research and Technology Development Fund of the Environmental Restoration and Conservation Agency of Japan (Grant No. JPMEERF20201001), and also JST SPRING (Grant No. JPMJSP2136).

Data availability All data sources used in the analyses, along with fully reproducible code, are publicly available at https://github.com/Micha elChaoLi-cpu/Air_Pollution_and_COVID-19_CFR.git.

\section{Declarations}

Ethics approval Not applicable.
Consent to participate All authors declare they have given consent to participate in this article.

Consent to publish All authors declare they have given consent to publish this article.

Competing interests The authors declare no competing interests.

\section{References}

Achebak H, Petetin H, Quijal-Zamorano M, Bowdalo D, Pérez GarcíaPando C, Ballester J (2021) Trade-offs between short-term mortality attributable to NO2 and O3 changes during the COVID-19 lockdown across major Spanish cities. Environ Pollut 286:117220

Benmarhnia T (2020) Linkages between air pollution and the health burden from COVID-19: Methodological challenges and opportunities. Am J Epidemiol 189:1238-1243

Brunekreef B, Holgate ST (2002) Air pollution and health. Lancet 360:1233-1242

Brunsdon C, Fotheringham S, Charlton M (1998) Geographically weighted regression. J R Stat Soc Ser D (The Statistician) 47:431-443

Buoli M, Grassi S, Caldiroli A, Carnevali GS, Mucci F, Iodice S, Cantone L, Pergoli L, Bollati V (2018) Is there a link between air pollution and mental disorders? Environ Int 118:154-168

Cao Y, Hiyoshi A, Montgomery S (2020) COVID-19 case-fatality rate and demographic and socioeconomic influencers: worldwide spatial regression analysis based on country-level data. BMJ Open 10:e043560

Chang S, Pierson E, Koh PW, Gerardin J, Redbird B, Grusky D, Leskovec J (2020) Mobility network models of COVID-19 explain inequities and inform reopening. Nature

Chin MT (2015) Basic mechanisms for adverse cardiovascular events associated with air pollution. Heart 101:253-256

Cortis D (2020) On Determining the Age Distribution of COVID-19 Pandemic. Front Public Health 8

Cruz-Sanchez TM, Haddrell AE, Hackett TL, Singhera GK, Marchant D, Lekivetz R, Meredith A, Horne D, Knight DA, Van Eeden SF, Bai TR, Hegele RG, Dorscheid DR, Agnes GR (2013) Formation of a Stable mimic of ambient particulate matter containing viable infectious respiratory syncytial virus and its dry-deposition directly onto cell cultures. Anal Chem 85:898-906

Dedoussi IC, Eastham SD, Monier E, Barrett SRH (2020) Premature mortality related to United States cross-state air pollution. Nature 578:261-265

Fernández D, Giné-Vázquez I, Liu I, Yucel R, Nai Ruscone M, Morena M, García VG, Haro JM, Pan W, Tyrovolas S (2021) Are environmental pollution and biodiversity levels associated to the spread and mortality of COVID-19? A four-month global analysis. Environ Pollut 271:116326

Ferrari U, Exner T, Wanka ER, Bergemann C, Meyer-Arnek J, Hildenbrand B, Tufman A, Heumann C, Huber RM, Bittner M, Fischer R (2012) Influence of air pressure, humidity, solar radiation, temperature, and wind speed on ambulatory visits due to chronic obstructive pulmonary disease in Bavaria, Germany. Int J Biometeorol 56:137-143

Fisman DN, Bogoch I, Lapointe-Shaw L, McCready J, Tuite AR (2020) Risk factors associated with mortality among residents with coronavirus disease 2019 (COVID-19) in long-term care facilities in Ontario, Canada. JAMA Netw Open 3:e2015957

Fotheringham AS, Oshan TM (2016) Geographically weighted regression and multicollinearity: dispelling the myth. J Geogr Syst 18:303-329 
Gollini I, Lu B, Charlton M, Brunsdon C, Harris P (2015): GWmodel: an R package for exploring spatial heterogeneity using geographically weighted models. J Stat Softw 63

Guan D, Wang D, Hallegatte S, Davis SJ, Huo J, Li S, Bai Y, Lei T, Xue Q, Coffman DM, Cheng D, Chen P, Liang X, Xu B, Lu X, Wang S, Hubacek K, Gong P (2020) Global supply-chain effects of COVID-19 control measures. Nat Hum Behav 4:577-587

Guo D, Wang A, Zhang AT (2020) Pollution exposure and willingness to pay for clean air in urban China. J Environ Manag 261:110174

Haque SE, Rahman M (2020) Association between temperature, humidity, and COVID-19 outbreaks in Bangladesh. Environ Sci Pol 114:253-255

Hsiang S, Allen D, Annan-Phan S, Bell K, Bolliger I, Chong T, Druckenmiller H, Huang LY, Hultgren A, Krasovich E, Lau P, Lee J, Rolf E, Tseng J, Wu T (2020) The effect of large-scale anti-contagion policies on the COVID-19 pandemic. Nature 584:262-267

Ikram M, Shen Y, Ferasso M, D’Adamo I (2021) Intensifying effects of COVID-19 on economic growth, logistics performance, environmental sustainability and quality management: evidence from Asian countries. J Asia Bus Stud ahead-of-print

Ikram M, Zhang Q, Sroufe R, Ferasso M (2020) The social dimensions of corporate sustainability: an integrative framework including COVID-19 insights. Sustainability 12:8747

Imbulana Arachchi J, Managi S (2021) The role of social capital in COVID-19 deaths. BMC Public Health 21

Ioannidis JPA, Axfors C, Contopoulos-Ioannidis DG (2020) Population-level COVID-19 mortality risk for non-elderly individuals overall and for non-elderly individuals without underlying diseases in pandemic epicenters. Environ Res 188:109890

Irfan M, Ikram M, Ahmad M, Wu H, Hao Y (2021) Does temperature matter for COVID-19 transmissibility? Evidence across Pakistani provinces. Environ Sci Pollut Res 28:59705-59719

Jiang Y, Xu J (2021) The association between COVID-19 deaths and short-term ambient air pollution/meteorological condition exposure: a retrospective study from Wuhan, China. Air Qual Atmos Health 14:1-5

Katoto PDMC, Brand AS, Bakan B, Obadia PM, Kuhangana C, Kayembe-Kitenge T, Kitenge JP, Nkulu CBL, Vanoirbeek J, Nawrot TS, Hoet P, Nemery B (2021) Acute and chronic exposure to air pollution in relation with incidence, prevalence, severity and mortality of COVID-19: a rapid systematic review. Environ Health 20

Kopel J, Perisetti A, Roghani A, Aziz M, Gajendran M, Goyal H (2020) Racial and gender-based differences in COVID-19. Front Public Health 8

Kummu M, Taka M, Guillaume JHA (2018) Gridded global datasets for Gross domestic product and human development index over 1990-2015. Sci Data 5:180004

Lee C, Kwak S, Kim J (2021) Controlling COVID-19 outbreaks with financial incentives. Int J Environ Res Public Health 18:724

Lelieveld J, Evans JS, Fnais M, Giannadaki D, Pozzer A (2015) The contribution of outdoor air pollution sources to premature mortality on a global scale. Nature 525:367-371

Li C, Managi S (2021a) Spatial Variability of the relationship between air pollution and well-being. Sustain Cities Soc 103447

Li C, Managi S (2021b) Contribution of on-road transportation to PM2.5. Sci Rep 11

Li C, Managi S (2021c) Land cover matters to human well-being. Sci Rep:11

Li H, Xu X-L, Dai D-W, Huang Z-Y, Ma Z, Guan Y-J (2020) Air pollution and temperature are associated with increased COVID-19 incidence: a time series study. Int J Infect Dis 97:278-282

Liu N, Zhang F, Wei C, Jia Y, Shang Z, Sun L, Wu L, Sun Z, Zhou Y, Wang Y, Liu W (2020) Prevalence and predictors of PTSS during COVID-19 outbreak in China hardest-hit areas: Gender differences matter. Psychiatry Res 287:112921
Magazzino C, Mele M, Sarkodie SA (2021) The nexus between COVID-19 deaths, air pollution and economic growth in New York state: Evidence from Deep Machine Learning. J Environ Manag 286:112241

Magazzino C, Mele M, Schneider N (2020) The relationship between air pollution and COVID-19-related deaths: an application to three French cities. Appl Energy 279:20

McClymont H, Hu W (2021) Weather variability and COVID-19 transmission: a Review of Recent Research. Int J Environ Res Public Health 18:396

Mollalo A, Rivera KM, Vahabi N (2021) Spatial statistical analysis of pre-existing mortalities of 20 diseases with COVID-19 mortalities in the continental United States. Sustain Cities Soc 102738

Mollalo A, Vahedi B, Rivera KM (2020) GIS-based spatial modeling of COVID-19 incidence rate in the continental United States. Sci Total Environ 728:138884

Nakamura H, Managi S (2020) Airport risk of importation and exportation of the COVID-19 pandemic. Transp Policy 96:40-47

Nishiga M, Wang DW, Han Y, Lewis DB, Wu JC (2020) COVID-19 and cardiovascular disease: from basic mechanisms to clinical perspectives. Nat Rev Cardiol 17:543-558

Ogen Y (2020) Assessing nitrogen dioxide (NO2) levels as a contributing factor to coronavirus (COVID-19) fatality. Sci Total Environ 726:138605

Onder G, Rezza G, Brusaferro S (2020) Case-Fatality Rate and Characteristics of Patients Dying in Relation to COVID-19 in Italy. JAMA

Oshan TM, Smith JP, Fotheringham AS (2020) Targeting the spatial context of obesity determinants via multiscale geographically weighted regression. Int J Health Geogr 19

Pope CA, Ezzati M, Cannon JB, Allen RT, Jerrett M, Burnett RT (2018) Mortality risk and PM2.5 air pollution in the USA: an analysis of a national prospective cohort. Air Qual Atmos Health $11: 245-252$

Popovic I, Soares Magalhaes RJ, Ge E, Marks GB, Dong G-H, Wei X, Knibbs LD (2019) A systematic literature review and critical appraisal of epidemiological studies on outdoor air pollution and tuberculosis outcomes. Environ Res 170:33-45

Shim E (2021) Regional Variability in COVID-19 Case Fatality Rate in Canada, February-December 2020. Int J Environ Res Public Health 18:1839

Silva Moreira P, Ferreira S, Couto B, Machado-Sousa M, Fernández M, Raposo-Lima C, Sousa N, Picó-Pérez M, Morgado P (2021) Protective elements of mental health status during the COVID-19 outbreak in the Portuguese Population. Int J Environ Res Public Health 18:1910

Slater SJ, Christiana RW, Gustat J (2020) Recommendations for Keeping parks and green space accessible for mental and physical health during COVID-19 and other pandemics. Prev Chronic Dis 17

Tilman D, Clark M (2014) Global diets link environmental sustainability and human health. Nature 515:518-522

Travaglio M, Yu Y, Popovic R, Selley L, Leal NS, Martins LM (2021) Links between air pollution and COVID-19 in England. Environ Pollut 268:115859

Wang D, Hu B, Hu C, Zhu F, Liu X, Zhang J, Wang B, Xiang H, Cheng Z, Xiong Y, Zhao Y, Li Y, Wang X, Peng Z (2020) Clinical characteristics of 138 hospitalized patients with 2019 novel coronavirus-infected pneumonia in Wuhan, China. JAMA 323:1061

Williamson EJ et al (2020) Factors associated with COVID-19-related death using OpenSAFELY. Nature 584:430-436

Wisnu Wardana VA, Rosyid AN (2021) Inflammatory Mechanism and clinical implication of asthma in COVID-19. Clin Med Insights Circ Respir Pulmn Med 15:117954842110427

WorldPop (2019) Global High Resolution Population Denominators Project 
Wu X, Nethery RC, Sabath MB, Braun D, Dominici F (2020) Air pollution and COVID-19 mortality in the United States: strengths and limitations of an ecological regression analysis. Sci Adv 6:eabd4049

Xing Y-F, Xu Y-H, Shi M-H, Lian Y-X (2016) The impact of PM2.5 on the human respiratory system. J Thorac Dis 8:E69-E74

Xue T, Guan T, Zheng Y, Geng G, Zhang Q, Yao Y, Zhu T (2021) Long-term PM2.5 exposure and depressive symptoms in China: a quasi-experimental study. Lancet Reg Health West Pac 6:100079

Yalaman A, Basbug G, Elgin C, Galvani AP (2021) Cross-country evidence on the association between contact tracing and COVID19 case fatality rates. Sci Rep: 11

Yoo S, Managi S (2020) Global mortality benefits of COVID-19 action. Technol Forecast Soc Chang 160:120231

Zhang X, Tang M, Guo F, Wei F, Yu Z, Gao K, Jin M, Wang J, Chen K (2021) Associations between air pollution and COVID-19 epidemic during quarantine period in China. Environ Pollut 268:115897

Zhang Z, Xue T, Jin X (2020) Effects of meteorological conditions and air pollution on COVID-19 transmission: Evidence from 219 Chinese cities. Sci Total Environ 741:140244
Zheng P, Chen Z, Liu Y, Song H, Wu C-H, Li B, Kraemer MUG, Tian H, Yan X, Zheng Y, Stenseth NC, Jia G (2021) Association between coronavirus disease 2019 (COVID-19) and long-term exposure to air pollution: Evidence from the first epidemic wave in China. Environ Pollut 276:116682

Zhu L, Hao Y, Lu Z-N, Wu H, Ran Q (2019) Do economic activities cause air pollution? Evidence from China's major cities. Sustain Cities Soc 49:101593

Zhu Y, Xie J, Huang F, Cao L (2020) Association between short-term exposure to air pollution and COVID-19 infection: Evidence from China. Sci Total Environ 727:138704

Zoran MA, Savastru RS, Savastru DM, Tautan MN (2020) Assessing the relationship between surface levels of PM2.5 and PM10 particulate matter impact on COVID-19 in Milan, Italy. Sci Total Environ 738:139825

Publisher's note Springer Nature remains neutral with regard to jurisdictional claims in published maps and institutional affiliations. 